\title{
Regional and age-specific patterns of pandemic H1N1 influenza virus seroprevalence inferred from vaccine clinical trials, August-October 2009
}

T F Tsai (theodore.tsai@novartis.com) ${ }^{1}$, P Pedotti ${ }^{2}$, A Hilbert $^{3}$, K Lindert $^{1}$, M Hohenboken $^{1}$, A Borkowski ${ }^{3}$, N Groth $^{4}$, L J da Silva ${ }^{1}$, M H Kyaw ${ }^{1}$

1. Novartis Vaccines and Diagnostics, Cambridge, Massachusetts, United States

2. Novartis Vaccines and Diagnostics, Amsterdam, the Netherlands

3. Novartis Vaccines and Diagnostics, Marburg, Germany

4. Novartis Vaccines and Diagnostics, Siena, Italy

The extent of the $\mathrm{H}_{1} \mathrm{~N}_{1}$ pandemic has been estimated from case counts and deaths but the proportion of exposed populations with inapparent infections has not been described in detail. We analysed haemagglutination-inhibition ( $\mathrm{HI}$ ) antibody titres of pre-vaccination sera from pandemic vaccine trials conducted in six countries on four continents to provide an indication of $\mathrm{A} / \mathrm{CA} / 07 / 2009\left(\mathrm{H}_{1} \mathrm{~N}_{1}\right)$-like influenza seroprevalence in those populations. Among 7,962 subjects, ranging in age from 12 months to over 60 years, the proportions with $\mathrm{HI}$ antibody titres $\geq 40$ to the $\mathrm{H}_{1} \mathrm{~N} 1 \mathrm{pnd}$ virus in the period from August to October 2009 were, by country: Costa Rica $26.4 \%$, United States (US) $22.5 \%$, Switzerland $16.9 \%$, Germany $12.6 \%$, Belgium $10.1 \%$, and Japan $5.9 \%$. Age-specific seropositivity rates in the samples were higher in children and adolescents in Costa Rica and in the US than in Europe and in Japan. The low proportion of seropositive children in Europe and Japan suggests that little local viral transmission had occurred in those regions even as late as September and October 2009, while in the US and Costa Rica, the greater proportion of previously infected children and young adults suggested that a significant number of asymptomatic infections had occurred during the first pandemic wave. Nevertheless, in all locations, the majority of the population remained susceptible to the pandemic virus at the beginning of the influenza season in the northern hemisphere, justifying the implementation of public health interventions.

\section{Introduction}

Influenza A/CA/07/2009( $\mathrm{H}_{1} \mathrm{~N}_{1}$ )-like (abbreviated $\mathrm{H}_{1} \mathrm{~N}_{1}$ pnd in this paper) viruses spread globally within several months after their recognition in April 2009, resulting in the declaration of a pandemic just two months later [1-3]. The extent of the global outbreak has been gauged principally by counting reports of laboratory-confirmed clinical cases, hospitalisations and deaths, and by monitoring clinical visits for influenzalike illness. The former underestimates the number of clinical cases and the latter is compromised by a lack of specificity. Neither approach measures the extent of inapparent infection. In the wake of widespread epidemics in both the northern and southern hemisphere, population seroprevalence rates were not reported systematically. Data on the overall and age-specific prevalence of antibodies to the $\mathrm{H}_{1} \mathrm{~N}_{1}$ pnd virus provide a perspective on the timing of recent public health vaccination programmes and the pandemic's spread.

We examined pre-vaccination serum samples from pandemic vaccine trials conducted in four continents to provide a crude indication of the proportion of those populations with immunity to the $\mathrm{H}_{1} \mathrm{~N} 1$ pnd virus and, conversely, the proportion that potentially remained susceptible to infection.

\section{Methods}

We analysed baseline (pre-vaccination) antibodies to the $\mathrm{H}_{1} \mathrm{~N}_{1}$ nd virus among persons participating in vaccine clinical trials at 54 sites in the United States (US), seven in Germany, two in Belgium, one in Switzerland, and one each in Costa Rica and Japan. The clinical trials were conducted during the period from August to October 2009 and enrolled 7,962 persons, ranging in age from 12 months to over 60 years. All studies excluded from participation individuals who reported having had a confirmed influenza illness within the past 3 to 12 months (intervals varied by protocol). Studies in children were initiated after an independent safety monitoring committee had reviewed interim safety of the vaccine in adult subjects (Europe) or after a separate government decision (Japan), so their initial blood samples were taken several weeks after those in adult subjects. In the US and Costa Rica, adults and children were enrolled into their respective trials in parallel. 
Prevaccination serum samples were tested for haemagglutination-inhibition ( $\mathrm{HI}$ ) antibodies against influenza $\mathrm{A} / \mathrm{CA} / 07 / 2009\left(\mathrm{H}_{1} \mathrm{~N}_{1}\right)$ according to established protocols in a single laboratory (Novartis Vaccines serology laboratory) [4]. All sera were tested in duplicate in two separate runs and the final titre was the geometric mean of two readings.

Prevalence rates of $\mathrm{HI}$ antibodies with a titre $\geq 40$ were analysed by country and by age group. Data for individual European countries were similar and were combined. Crude country- and region-specific rates were not adjusted to standard populations. We chose an $\mathrm{HI}$ titre $\geq 40$ as a cut-off to represent $\mathrm{H}_{1} \mathrm{~N}_{1}$ pnd virus-specific antibodies and to reduce the likelihood of misclassifying cross-reactive antibodies ( $\geq 10)$ [5].

\section{Results}

The numbers and proportion of subjects with $\mathrm{H}_{1} \mathrm{~N}_{1}$ pnd $\mathrm{HI}$ antibodies are shown by country and age group in Figures 1 and 2. The estimated prevalence of $\mathrm{HI}$ antibodies to $\mathrm{H}_{1} \mathrm{~N}_{1}$ nnd varied substantially by geographical location and age group (studies in the US were not designed to include children 9-17 years old). Overall, seropositivity rates (proportion with $\mathrm{HI}$ titres $\geq 40$ ) were higher in cohorts from Costa Rica (26.4\%, enrolled during August 18-August 31) and from the US (22.5\%, enrolled 11-25 September) compared with those in Switzerland (16.9\%, enrolled 8-26 August), Germany (12.6\%, enrolled 8 August-29 September), Belgium (10.1\% enrolled 8 August-2 October) and Japan (5.9\%, enrolled 16 September-2 October). The age-specific seropositivity rate in the Costa Rica sample was highest in older children, while in Europe and Japan, rates were higher in adults and were low in children. In the US sample, the proportion of seropositives was two- to three-fold lower in children between three and eight years of age (11.2\%) compared with adults (24.9\%) and the elderly (31.2\%).
The regional and age-specific patterns of subjects with an $\mathrm{HI}$ titre $\geq 10$ were similar but were proportionately higher, except in Costa Rica (Figures 1 and 2).

\section{Discussion and conclusions}

We observed regional differences in overall and agespecific $\mathrm{H}_{1} \mathrm{~N}_{1}$ pnd seropositivity rates (defined as an $\mathrm{HI}$ titre of $\geq 40$ ) in the period from August through October 2009 that may have reflected the manner of introduction of the pandemic virus to the respective areas and subsequent patterns of local transmission. While the virus was introduced by infected travellers from North America to distant points, including Europe, Asia, and Oceania, within weeks of its emergence, the extent to which the virus was seeded into those populations and the rapidity of local spread appears to have differed. In Costa Rica, the virus may have been introduced with contiguous expansion of the regional epidemic through Central America from Mexico, as well as directly, by travellers.

Reported surveillance data on influenza like illness (ILI) indicate that baseline serum specimens were taken during the peak of ILI activity in Costa Rica and during the early upswing of renewed epidemic transmission in the US, but that the vaccine trials in Europe and in Japan largely preceded the onset of respective local epidemics [6-8]. The high overall seropositivity rate in Costa Rica and the peak rate occurring in older children are consistent with the epidemiology of the pandemic. In the US, our trial and another conducted in the same time-frame [9] did not study 9-17 year-olds, thus, the overall proportion of seropositive subjects, $22.5 \%$ in this study, is likely to underestimate the proportion of the US population that was asymptomatically infected.

In Europe and in Japan, lower overall antibody prevalence rates prevailed at the time that the serum samples were taken, suggesting that local transmission

\section{FIGURE 1}

Proportion of clinical trial subjects with H1N1pnd haemagglutination inhibition antibody titres $\geq 10$ and $\geq 40$, by country, August-October 2009

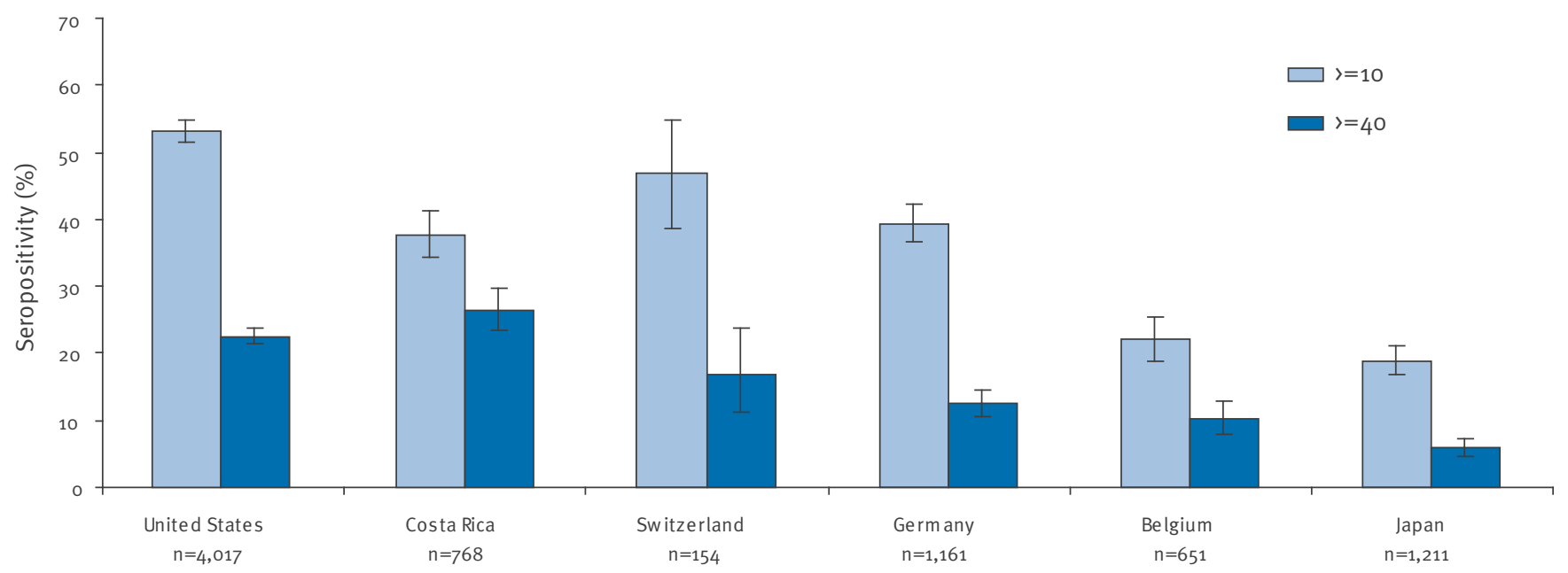

H1N1pnd: Influenza A/CA/07/2009( $\left.\mathrm{H}_{1} \mathrm{~N}_{1}\right)$-like virus; $n$ : total number of subjects. 
still was limited in Europe in September, and as late as October in Japan. These low seroprevalence rates were consistent with reports from vaccine studies conducted before 18 September in Europe and China that reported, respectively, $0-8 \%$ and $4 \%$ of subjects had baseline $\mathrm{HI}$ titres $\geq 40$ [9-13]. In contrast, approximately one third of adult and older paediatric subjects who were vaccinated in the midst of the epidemic in the southern hemisphere in July and August 2009 had baseline antibody titres $\geq 40[14,15]$. The low proportion

\section{FIGURE 2}

Proportion of clinical trial subjects with H1N1pnd haemagglutination inhibition antibody titres $\geq 10$ and $\geq 40$, by country or region and by age group, August-October 2009
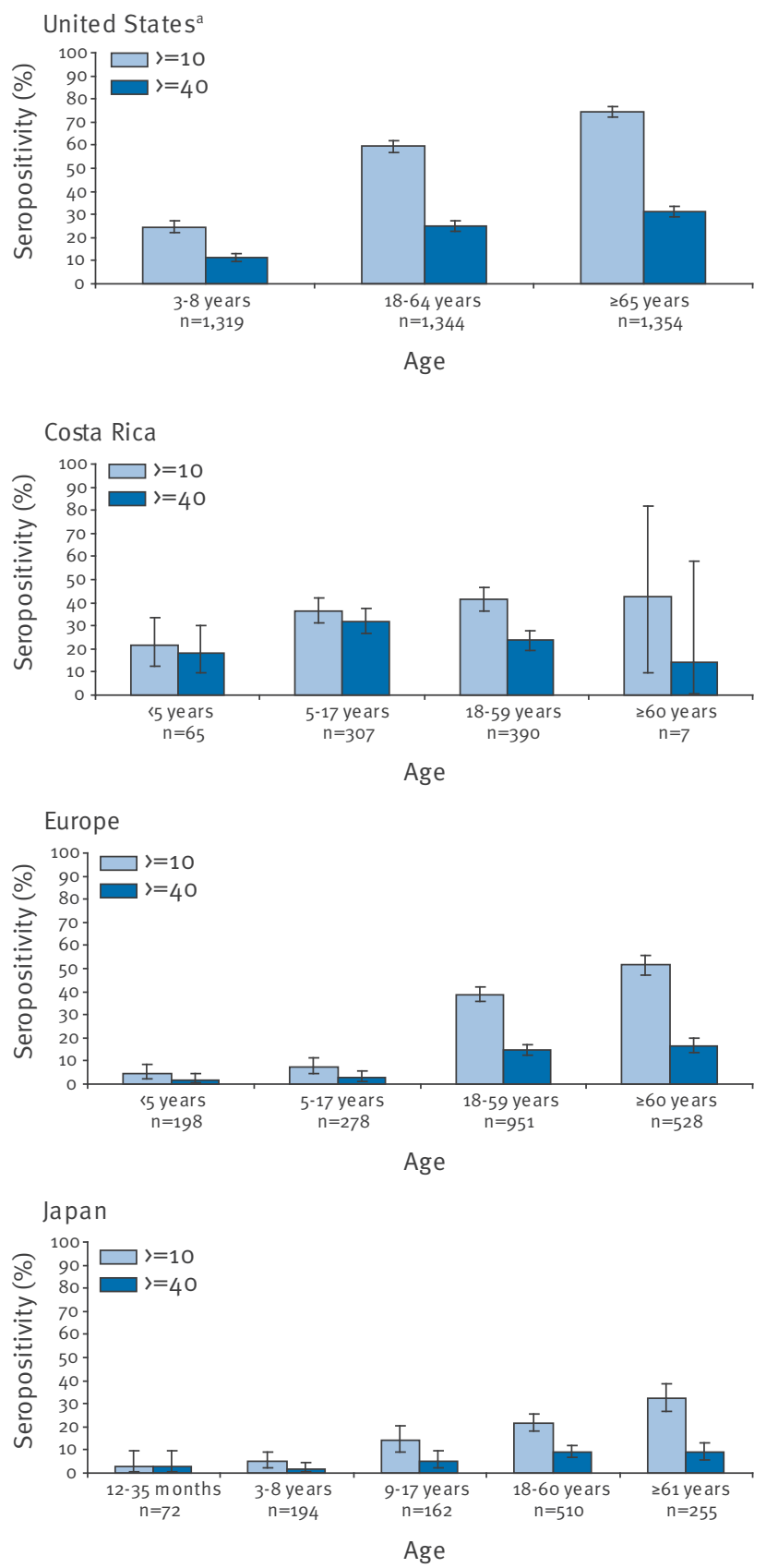

$\mathrm{H}_{1} \mathrm{~N}_{1}$ nd: Influenza A/CA/07/2009(H1N1)-like virus; $\mathrm{n}$ : total number of subjects.

${ }^{\text {a }}$ A separate cohort of 9-17 year-olds was not evaluated in US trials. of seropositives in the oldest Japanese age group, approximately one third lower than the $34 \%$ prevalence previously reported in the elderly in the US [5] and in our US sample is notable, potentially reflecting the absence of routine seasonal influenza vaccination of the elderly in Japan and perhaps, even a residual effect of the US 1976 swine influenza vaccination campaign.

The last two weeks of August, when the European trials were initiated, is a period when many Europeans return from holidays but before schools reopen. Despite the fact that baseline serum samples were obtained later from children than from adults, the infection rate in children was remarkably low, suggesting that even through September, relatively little local transmission had occurred. At that point in time, it appears that antibodies among adults in Europe (and also in Japan) still were more likely to reflect a combination of recent pandemic infections in returned travellers and past infections with older, related $\mathrm{H}_{1} \mathrm{~N}_{1}$ viruses rather than local transmission. Of interest, a more systematic and detailed analysis of the population of the United Kingdom (UK) showed that by August, a higher proportion of serum samples submitted for testing were seropositive ( $\mathrm{HI}$ titres 232 ) than among our samples from continental Europe which were closer to the 2008 UK baseline rates [16]. That discrepancy and differences within the UK itself during the outbreak [16] further underscore the non-uniform dispersion of the pandemic virus even within a continent.

Serological studies of US and European serum samples obtained prior to the pandemic showed that fewer than $7 \%$ of persons under 65 years of age and none of the young children were seropositive for the H1N1pnd virus [5]. In these same age groups, we saw a substantially higher proportion of seropositives (e.g. $120 \%$ in Costa Rica) by late August and September, suggesting that a significant fraction of the populations of some countries had been asymptomatically infected with the pandemic virus towards the end of the epidemic's first wave, and just four to five months after the index cases were reported. Unfortunately, data were not collected from the US for the age group of 9-17 year-olds, in whom a greater proportion of infections might have been expected, so the overall seroprevalence estimate for the US is likely to be understated. Nevertheless, the great majority of subjects had $\mathrm{HI}$ antibodies titres $<40$ and potentially were susceptible to infection even at this point in early autumn.

The seropositivity proportions reported here derive from convenience samples of healthy persons willing to participate in vaccine clinical trials and who did not report a history of recent influenza illness and, therefore may not be representative of their respective national populations. The proportions provide some indication of age-specific seroprevalence rates in the respective countries in the period from August to October 2009 at various stages of their local epidemic but, in general, before the major resurgence of autumn 
transmission in the northern hemisphere. Clinical trial subjects were enrolled from a variable number of sites in each country and local infection rates may not have reflected national trends, although the more than 4,000 samples and 54 sites dispersed in the US provide for a more robust estimate for that country than in the other countries.

Minimal antigenic cross-reactivity between $\mathrm{H}_{1} \mathrm{~N} 1 \mathrm{pnd}$ and recently circulating seasonal $\mathrm{H}_{1} \mathrm{~N}_{1}$ strains has been demonstrated and, in the absence of specific clinical data correlating with protection, we used an $\mathrm{HI}$ titre of $\geq 40$ previously to define $\mathrm{H}_{1} \mathrm{~N}_{1}$ pnd-specific immunity in order to exclude antibodies cross-reactive with previously circulating seasonal influenza $A\left(\mathrm{H}_{1} \mathrm{~N}_{1}\right)$ viruses [5].

Although our point estimates of seropositivity indicate that a significant proportion of the US and Costa Rica populations sampled may have been asymptomatically infected with the H1N1pnd virus, it is important to note that at the start of the usual northern hemisphere influenza season, a majority of people in all regions and in particular in Europe, did not have antibodies to the pandemic virus at putatively protective levels. Large scale vaccination programmes were therefore in order to protect individuals at risk for acquiring influenza illness and its complications, and to further limit transmission.

The seropositivity rates reported here also are important to guide the interpretation of vaccine clinical trials. Responses to the $\mathrm{H}_{1} \mathrm{~N}_{1}$ pnd vaccine vary significantly between seronegative and seropositive persons (Novartis, unpublished data). Because most pandemic vaccine clinical trials have been undertaken during periods of active viral transmission, the results should be interpreted in the context of the level of pre-vaccination antibodies.

\section{Conflicts of interest}

All authors are full time employees of Novartis Vaccines, a manufacturer of pandemic influenza virus vaccines.
5. Hancock K, Veguilla V, Lu X, Zhong W, Butler EN, Sun H, et al. Cross-reactive antibody responses to the 2009 pandemic $\mathrm{H}_{1} \mathrm{~N}_{1}$ influenza virus.N Engl J Med. 2009;361(20):1945-52.

6. Regional Update. Pandemic $\left(\mathrm{H}_{1} \mathrm{~N}_{1}\right)$ 2009. Washington D.C.: Pan American Health Organization (PAHO); 22 December 2009. [Accessed 23 December 2009. Available from: http://new.paho. $\mathrm{org} / \mathrm{hq} /$ index.php?option=com_content\&task=blogcategory\&i $\mathrm{d}=1845$ \&Itemid $=2336$

7. WHO/Europe influenza surveillance (EuroFlu.org). Copenhagen: World Health Organization European Region. [Accessed 21 Dec 2009]. Available from: http://www.euroflu.org

8. Pandemic $\left(\mathrm{H}_{1} \mathrm{~N}_{1}\right)_{2}$ 2009. Current Situation update. Pandemic influenza $A\left(\mathrm{H}_{1} \mathrm{~N}_{1}\right)$ situation report of Japan, update 26.18 December 2009. Tokyo: Infectious Disease Surveillance Center (IDSC). [Accessed 21 Dec 2009]. Available from: http://idsc.nih. go.jp/disease/swine_influenza_e/idsc_e2009/ogidsc26e.html

9. Plennevaux E, Sheldon E, Blatter M, Reeves-Hoche MK Denis $M$. Immune response after a single vaccination against 2009 influenza a $\mathrm{H}_{1} \mathrm{~N}_{1}$ in USA: a preliminary report of two randomised controlled phase 2 trials. Lancet. 2009;375(9708):41-8.

10. Vajo Z, Tamas F, Sinka L, Jankovics I. Safety and immuinogenicity of a 2009 pandemic influenza $A \mathrm{H}_{1} \mathrm{~N}_{1}$ vaccine when adminsitered alone or simultaneously with the seasonal influenza vaccine for the 2009-10 influenza season: a multicentre, randomised controlled trial. Lancet 2009;375(9708):49-55.

11. Lian XF, Wang HQ, Wang JZ, Fang HH, Wu J, Zhu FC, et al. Safety and immunogenicity of 2009 pandemic influenza $A_{1} \mathrm{H}_{1}$ vaccines in China: a multicentre, double-blind, randomised, placebo-controlled trial. Lancet. 2010;375(9708):56-66.

12. Clark TW, Pareek M, Hoschler K, Dillon H, Nicholson KG, Groth $\mathrm{N}$, et al. Trial of 2009 influenza $\mathrm{A}\left(\mathrm{H}_{1} \mathrm{~N}_{1}\right)$ monovalent MF59adjuvanted vaccine. New Eng J Med. 2009;361(25):2424-35.

13. Ikonen N, Strengell M, Kinnunen L, Österlund P, Pirhonen J, Broman $M$, et al. High frequency of cross-reacting antibodies against 2009 pandemic influenza $\mathrm{A}\left(\mathrm{H}_{1} \mathrm{~N}_{1}\right)$ virus among the elderly in Finland. Euro Surveill. 2010;15(5):pii=19478. Available from: http://www.eurosurveillance.org/ViewArticle. aspx?Articleld $=19478$

14. Greenberg ME, Lai MH, Hartel GF, Wichems CH, Gittleson C, Bennet J, et al. Response to a monovalent 2009 influenza A $\left(\mathrm{H}_{1} \mathrm{~N}_{1}\right)$ vaccine. New Eng J Med. 2009;361(25):2405-13.

15. Nolan T, McVernon J, Skeljo, Richmond P, Wadia U, Lambert S, et al. Immunogenicity of a monovalent 2009 inflouenza $A\left(\mathrm{H}_{1} \mathrm{~N}_{1}\right)$ vaccine in infants and children: a randomized trial. JAMA. 2010;303(1):37-46.

16. Miller E, Hoschler K, Hardelid P, Stanford E, Andrews N, Zambon M. Incidence of 2009 pandemic influenza $\mathrm{A} \mathrm{H}_{1} \mathrm{~N}_{1}$ infection in England: a cross-sectional serological study. Lancet. 2010;375(9720):1100-8.

References

1. Centers for Disease Control and Prevention (CDC). Swine influenza $A\left(\mathrm{H}_{1} \mathrm{~N}_{1}\right)$ infection in two children---Southern California, March-April 2009. MMWR Morb Mortal Wkly Rep. 2009;58(15):400-2.

2. World now at the start of 2009 influenza pandemic Statement to the press by WHO Director-General Dr Margaret Chan. Geneva: World Health Organization; 11 June 2009. [Accessed 21 Dec 2009]. Available from: http://www.who.int/mediacentre/ news/statements/2009/h1n1_pandemic phase6_20090611 en/index.html

3. Khan K, Arino J, Hu W, Raposo P, Sears J, Calderon F, et al. Spread of a novel influenza $A\left(\mathrm{H}_{1} \mathrm{~N}_{1}\right)$ virus via global airline transportation. New Eng J Med. 2009;361(2):212-4.

4. Vesikari T, Pellegrini M, Karvonen A, Groth N, Borkowski A, O'Hagan DT, et al. Enhanced immunogenicity of seasonal influenza vaccines in young children using MF59 adjuvant. Pediatr Infect Dis J. 2009;28(7):563-71. 